\title{
Avaliação externa das escolas em Portugal: atores, conhecimentos, modos de regulação
}

\author{
External evaluation of schools in Portugal: actors, knowledge, \\ modes of regulation \\ Evaluación externa de las escuelas en Portugal: actores, conocimientos, \\ modos de regulación \\ LUÍS MIGUEL CARVALHO \\ ESTELA COSTA
}

Resumo: O artigo centra-se na construção e reconstrução do modelo de avaliação externa das escolas em Portugal em dois momento - 2006 e 2011 pondo em evidência continuidades e mudanças relacionadas com os atores e com os conhecimentos mobilizados para a construção dos modelos avaliativos, bem como o fortalecimento da avaliação como dispositivo de regulação das práticas de administração das escolas. $\mathrm{O}$ artigo mostra as vicissitudes da ativação de modos de intervenção avaliativos em agências da administração central da educação historicamente constituídas como agências de supervisão e controlo.

Palavras-chave: avaliação das escolas; hibridação; políticas públicas; regulação da educação.

Abstract: The article focuses on the construction and reconstruction of the
external evaluation model of Portuguese schools in two moments (2006 and
2011). The article highlights continuities and changes related to the actors and
the knowledge mobilized for the construction of the evaluation models, as well
as the strengthening of evaluation as a device for regulating the management
practices of the schools. The article shows the vicissitudes of the activation of
modes of evaluation intervention in agencies of the central administration of
education historically constituted as supervisory and control agencies.

Keywords: evaluation of schools; hybridization; public policy; regulation of education.

Resumen: El artículo se centra en la construcción y reconstrucción del modelo de evaluación externa de los centros educativos en Portugal, en dos momentos (2006 y 2011), evidenciando continuidades y cambios relacionados con los actores y con los conocimientos movilizados para la construcción de los modelos evaluativos, así como el fortalecimiento de la evaluación como dispositivo de regulación de las prácticas de administración de las escuelas. El artículo muestra las vicisitudes de la activación de modos de intervención evaluativos en agencias de la administración central de la educación históricamente constituidas como agencias de supervisión y control.

Palabras clave: evaluación de las escuelas; hibridación; políticas públicas; regulación de la educación. 


\section{INTRODUÇÃO: TENSÕES E HIBRIDAÇÕES NA REGULAÇÃO DA EDUCAÇÃO}

O surgimento e permanência, em toda a Europa, de estruturas e práticas de avaliação externa das escolas (AEE), é um indicador da ampla difusão e da relevância alcançada pelos "modelos de regulação pós-burocráticos" (MAROY, 2009). Não obstante essa presença de um ethos de avaliação, no setor educacional e o uso mais intenso do conhecimento avaliativo na direção dos sistemas educativos, as trajetórias dos modelos de avaliação escolar não são, em contextos nacionais, imunes aos processos conspícuos de mediação, reinterpretação e contextualização que ocorrem quando "políticas viajantes" (LINDBLAD; POPKEWITZ, 2004; OZGA; JONES, 2006) e formas específicas de conhecimento educacional fluem através dos contextos nacionais, regionais ou locais. Assim, a adoção e desenvolvimento nacional de modelos de avaliação das escolas é um possível lugar para a análise dos processos e efeitos da hibridização e de bricolagem que resultam da receção nacional de políticas e conhecimentos mundiais (ver, por exemplo, POPKEWITZ, 2000; VAN ZANTEN; BALL, 2000; BARROSO, 2005; MAROY, 2009; STEINER-KHAMSI, 2012). Além disso, a análise das dinâmicas e especificidades de tal receção pode, muito bem, permitir-nos melhorar nossa compreensão sobre as tensões e / ou combinações entre formas burocráticas e pós-burocráticas no governo da educação.

Neste artigo, analisamos a construção e reconstrução do modelo de AEE instituído pelas autoridades nacionais portuguesas ao longo da última década, enquanto analisador de duas facetas de hibridização que caracterizam os desenvolvimentos contemporâneos das políticas nacionais de educação e a regulação social e política dos sistemas educacionais: a combinação de modos regulatórios transnacionais e nacionais; a coexistência em âmbito nacional de formas burocráticas e pós-burocráticas de regulação (BARROSO, 2005; CARVALHO, 2015). Assim, trabalhamos a seguinte hipótese: a trajetória do modelo oficial de avaliação das escolas é marcada, em Portugal, tanto pelas forças exercidas pelos "padronizadores" internacionais (BRUNSSON \& JACOBSSON, 2000), que colocam em circulação as regras de "como fazer" a avaliação das escolas, quanto pelo efeito da mobilização dessas regras, à escala nacional, por atores heterogéneos, de acordo com seus conhecimentos e recursos para ação e com as especificidades dos sistemas de significados e das relações de poder dos contextos em que eles intervêm (ver POPKEWITZ, 2000).

Consequentemente, o artigo centra-se na trajetória da AEE em Portugal, que é um dos vários dispositivos utilizados na avaliação estatal, da educação primária e secundária, desde o início do presente século. Especificamente, 
concentramo-nos na construção e reconstrução do modelo oficial da AEE em dois momentos-chave da sua trajetória: a produção de sua primeira versão, em 2006, por um Grupo de Trabalho (GT) designado pelo governo; e sua revisão e atualização, em 2011, por um GT diferente, também nomeado pelo governo.

Concebemos o modelo oficial da AEE portuguesa como uma técnica que atualiza a avaliação escolar (externa). E analisamos a avaliação escolar (externa) como instrumento de política, ou seja, seguindo Lascoumes e Le Galès (2007), como "um dispositivo técnico e social que organiza relações sociais específicas entre o Estado e os destinatários, de acordo com as representações e significados que transporta" (p. 4). Segundo esta perspetiva analítica, a avaliação escolar transporta valores e interpretações sobre educação, e é orientada por noções explícitas de uma regulação prevista. Em outras palavras, é habitada por regras e procedimentos destinados a proporcionar estabilidade e previsibilidade à ação social no setor educacional. No entanto, se a avaliação das escolas estrutura a regulação do sistema educativo, de acordo com sua própria lógica, está também sujeita a controvérsias e modificações ao longo da sua trajetória. Por conseguinte, toda a pesquisa sobre a construção e reconstrução do modelo de avaliação das escolas deve buscar as configurações de atores, interesses, ideias e conhecimento que moldam a trajetória dos instrumentos de política, bem como as tensões, as continuidades e asmudanças na regulação do sistema educativo. É este nosso propósito neste estudo, com o objetivo de compreender como a hibridação - isto é, a recombinação e remodelação de elementos sociais e culturais (PIETERSE, 2000) - tem lugar na construção e reconstrução do modelo oficial da AEE, sob que formas e com que consequências (RIZVI; LINGARD, 2009).

Com base nessa perspetiva, desenvolvemos a pesquisa em torno de três eixos analíticos inter-relacionados: (1) o primeiro ('atores') observa os membros dos GT de 2006 e 2011 para descrever os diversos mundos sociais envolvidos na fabricação e na reelaboração do modelo; (2) o segundo ('conhecimento') considera as variadas fontes e tipos de conhecimento mobilizados para a construção dos modelos de avaliação; (3) o terceiro ('modos de regulação') examina as diversas conceções de administração social previstas e instituídas na construção e reconstrução do instrumento regulador. O estudo envolve análise documental, bem como dados de entrevistas em profundidade. Trabalhámos principalmente com documentos do banco de dados on-line da Inspeção portuguesa da educação (incluindo legislação, declarações políticas, documentos oficiais de planeamento, diretrizes operacionais, relatórios). Mobilizamos dados de entrevistas de um estudo de caso sobre o GT de 2006 (BARROSO et al., 2008), e 'entrevistas com dois atores participantes no GT de 2011 (E1 e E2), realizadas no quadro de um estudo que orientamos (ROCHA, 2012). 
O artigo está organizado em três partes. Na primeira, descrevemos as principais características de cada "contexto de produção" e de cada modelo de AEE. Na segunda parte, condensamos a análise de dados sobre a elaboração do modelo de AEE de 2006 e sua remodelação em 2011, discutindo três aspetos centrais: os atores envolvidos, os conhecimentos mobilizados e as formas de validação social e cognitiva dos modelos. A terceira parte analisa a regulação híbrida, que foi possível identificar nos documentos e intervenções dos atores, designadamente, através da importância atribuída ao impacto e sequencialidade da AEE à articulação de documentos e ao reforço da regulação de controlo por meio desses documentos. $\mathrm{O}$ artigo termina com notas conclusivas.

\section{OS MODELOS DA AVALIAÇÃO EXTERNA DAS ESCOLA EM PORTUGAL EM 2006 E 2011: UMA APRESENTAÇÃO SUMÁRIA}

Em 2006, o governo decidiu lançar um programa experimental sobre avaliação de escolas públicas, coordenado por um GT e envolvendo 24 escolas/ agrupamentos de escolas. Concluída essa intervenção, foi adotada uma política de avaliação externa, que incluiu o modelo proposto de AEE, confinada sua implementação à Inspeção da Educação. Um total de 1131 escolas e agrupamentos de escolas (E/AE) foi avaliado entre os anos escolares de 2006 e 2007 e 20102011 (GTAEE, 2011). Em 2011, um GT diferente, também nomeado pelo governo, foi constituído para rever o modelo e os processos de avaliação externa. As proposições desse GT foram adotadas e estiveram em uso até ao presente ano. O segundo ciclo da AEE teve início no ano letivo de 2011-2012, tendo sido avaliadas $812 \mathrm{E} / \mathrm{AE}^{1}$.

Os dois modelos comungam um conjunto de finalidades ou contribuições esperadas: para o conhecimento sobre práticas e resultados escolares; para a administração do sistema escolar e das escolas; para a informação e mobilização comunitária e societária. Não obstante, a preponderância conferida, no primeiro ciclo, a objetivos associados ao fomento da autoavaliação (AA) e da autonomia das escolas cede passo à avaliação do desempenho escolar dos alunos: o progresso das aprendizagens e dos resultados dos alunos (ver Figura 1)

1

Informação recolhida em www.ige.min-edu.pt/ 


\section{Figura 1 - Objetivos do Programa da AEE}

\begin{tabular}{|c|c|}
\hline 2006 & 2011 \\
\hline $\begin{array}{l}\text { Fomentar nas escolas uma interpelação } \\
\text { sistemática sobre a qualidade das suas } \\
\text { práticas e dos seus resultados } \\
\text { Articular os contributos da avaliação externa } \\
\text { com a cultura e os dispositivos de } \\
\text { autoavaliação das escolas } \\
\text { Reforçar a capacidade das escolas para } \\
\text { desenvolverem a sua autonomia } \\
\text { Concorrer para a regulação do } \\
\text { funcionamento do sistema educativo } \\
\text { Contribuir para um melhor conhecimento das } \\
\text { escolas e do serviço público de educação, } \\
\text { fomentando a participação social na vida das } \\
\text { escolas }\end{array}$ & $\begin{array}{l}\text { Promover o progresso das aprendizagens e } \\
\text { dos resultados dos alunos, identificando } \\
\text { pontos fortes e áreas prioritárias para a } \\
\text { melhoria do trabalho das escolas } \\
\text { Incrementar a responsabilização a todos os } \\
\text { niveis, validando as práticas de autoavaliação } \\
\text { das escolas } \\
\text { Fomentar a participação na escola da } \\
\text { comunidade educativa e da sociedade local, } \\
\text { oferecendo um melhor conhecimento público } \\
\text { da qualidade do trabalho das escolas } \\
\text { Contribuir para a regulação da educação, } \\
\text { dotando os responsáveis pelas politicas } \\
\text { educativas e pela administração das escolas } \\
\text { de informação pertinente }\end{array}$ \\
\hline
\end{tabular}

Fonte: IGE (2009, p. 7), GTAEE (2011, p. 42)

$\mathrm{Na}$ Figura 2, apresentamos as principais características e diferenças das duas propostas.

Figura 2 - Os modelos de avaliacão externa de 2006 e de 2011

\begin{tabular}{|c|c|c|}
\hline Dimensões & Modelo 2006 & Modelo 2011 \\
\hline $\begin{array}{c}\text { Natureza da participação das } \\
\text { escolas }\end{array}$ & Voluntária & Compulsiva \\
\hline Dominios da avaliação & $\begin{array}{l}\text { Resultados - Prestação do serviço } \\
\text { - Organização e gestão escolar - } \\
\text { Liderança - Capacidade de } \\
\text { autorregulação e melhoria da } \\
\mathrm{E} / \mathrm{AE}\end{array}$ & $\begin{array}{l}\text { Resultados - Prestação do serviço } \\
\text { educativo - Liderança e gestão }\end{array}$ \\
\hline $\begin{array}{l}\text { Procedimentos anteriores à } \\
\text { visita às escolas }\end{array}$ & $\begin{array}{l}\text { Texto de apresentação da escola - } \\
\text { Documentos orientadores da } \\
\text { gestão da escola - Dados } \\
\text { estatisticos da escola }\end{array}$ & $\begin{array}{l}\text { Idêntico + Perfil da escola [incluindo } \\
\text { valor esperado na análise dos resultados } \\
\text { das escolas, elaborado por serviço } \\
\text { central] + Questionários de satisfação }\end{array}$ \\
\hline Equipa de avaliadores & $\begin{array}{l}2 \text { Inspetores }+1 \text { avaliador externo } \\
\qquad \mathbf{a} \text { inspeção }\end{array}$ & $\begin{array}{c}\text { Composição idêntica (possivel mais } 1 \\
\text { em estabelecimentos de maior } \\
\text { dimensão) }\end{array}$ \\
\hline $\begin{array}{l}\text { Procedimentos da visita às } \\
\text { escolas }\end{array}$ & $\begin{array}{l}\text { Visita às instalações ( } 2-3 \text { dias) } \\
\text { Entrevistas em painel (11) com } \\
\text { membros de estruturas de gestão } \\
\text { escolar e da comunidade escolar }\end{array}$ & Idêntico \\
\hline $\begin{array}{c}\text { Processos e produtos } \\
\text { posteriores à visita às escolas }\end{array}$ & $\begin{array}{c}\text { Relatório } \\
\text { Publicação resultados }\end{array}$ & $\begin{array}{c}\text { Idêntico + Apresentação pela escola de } \\
\text { Plano de Melhoria }\end{array}$ \\
\hline
\end{tabular}




\section{OS ATORES E OS CONHECIMENTOS DA MODELIZAÇÃO DA AVALIAÇÃO EXTERNA EM PORTUGAL: DA EXTERIORIDADE À INTERIORIDADE}

\section{Os atores reunidos}

A elaboração do modelo de avaliação, em 2006, resultou de um conjunto de atores (seis elementos) provenientes da academia e funcionários seniores da administração central, cujas trajetórias profissionais ocorreram na encruzilhada de muitos mundos sociais: três professores/pesquisadores, um ex-inspetor geral da educação, um alto funcionário do governo, que também era ex-inspetor-geral da educação e estava, nessa época, provendo assessoria científica estratégica ao gabinete do ministro da educação. Além disso, esses atores têm suas trajetórias profissionais marcadas por atividades que realizaram, como especialistas, em contextos avaliativos: envolvimento em projetos de apoio à tomada de decisão na avaliação de cursos de educação superior; experiência de avaliação e gestão do desempenho dos serviços públicos nos campos da educação e do ensino superior; participação em vários projetos nacionais e internacionais; coordenação e gestão de várias equipas na área de avaliação curricular, sucesso educativo e desempenho escolar e também uma ampla publicação nesta área; anterior lançamento de um programa de avaliação nacional da escola; envolvimento com organizações internacionais envolvidas na avaliação escolar, representando Portugal no 'Indicators of Education Programme' (INES) da Organização para a Cooperação e Desenvolvimento Económico (OCDE) e na Standing International Conference of Inspectorates (SICI). Finalmente, os atores que tiveram maior centralidade na elaboração do modelo de 2006 foram aqueles que, além de terem tido uma experiência relevante anterior, na Inspeção, poderiam desempenhar o papel de mediação, na medida em que ocupavam posições intersticiais entre mundos e entre diferentes escalas no exterior (OCDE e SICI) e em Portugal (gabinete ministerial, administração central e universidade).

Em 2011, com o remake do modelo de AEE, é evidente um peso maior, no GT, dos atores relacionados com a Inspeção. O grupo ampliou-se, de seis para oito elementos, principalmente da Inspeção (que constituía metade do grupo, incluindo seu coordenador). Encontramos uma confluência de atores sociais de mundos idênticos ou iguais (quatro são inspetores de educação, um ex-Inspetor Geral da Educação; um doutor em 'Filosofia em Administração e Supervisão Educacional; e dois investigadores/professores universitários). Assim, a externalização à perícia dá lugar à internalização dos assuntos. Embora esses atores tenham suas trajetórias marcadas por atividades onde atuam como 
especialistas em contextos avaliativos, a diferença, em relação a 2006, ocorre ao nível da amplitude e profundidade das experiências, integrando equipas de avaliação na qualidade de peritos; coordenando e gerindo equipas na área de avaliação curricular, sucesso educativo e desempenho escolar; e integrando o Painel de Avaliadores, no Programa de Avaliação Institucional da Associação Europeia de Universidades.

\section{Os conhecimentos mobilizados}

A elaboração do modelo de 2006 resultou do entrelaçamento de conhecimento heterogéneo, decorrente das experiências dos atores no design e/ou gestão de dispositivos de avaliação e importados de modelos disseminados por organizações de outros países. Em relação às experiências dos atores, na conceção e/ou gestão de dispositivos de avaliação, nota-se: o envolvimento na avaliação do setor público R\&D; participação na aplicação de metodologias de apoio à decisão para processos de avaliação e gestão na universidade; um programa de avaliação escolar anterior - a "avaliação integrada da escola" - que tinha sido realizado pela Inspeção entre 1999 e 2002. Quanto aos modelos, os mais relevantes são o manual de AA escolar da Escócia, 'How Good is our School'; o documento do Departamento de Educação da Irlanda do Norte, intitulado 'A process for self-evaluation'; o projeto 'Effective School Self-Evaluation' (ESSE) efetuado pela SICI; o 'European Pilot Project for Self-Evaluation of Schools' e seus desenvolvimentos; o modelo 'Total Quality Management' ou a metodologia 'European Foundation for Quality Management'.

A revisão do modelo de avaliação, em 2011, toma a "qualidade" (das escolas, da educação) como referencial orientador e toma a 'contribuição para a garantia da qualidade" como função primordial da AEE (GTAEE, 2011, p. 9, 21). Retoma, assim, o mesmo referencial adotado no ciclo anterior, que havia já sido mobilizado para orientar iniciativas desenvolvidas pela Inspeção desde o final do século passado (AFONSO; COSTA, 2012).O que é relevante nesta reafirmação é o tipo de fontes mobilizadas para a legitimação do documento e sua ordem de entrada em cena da elaboração do argumento: externamente, as organizações internacionais 'de referência' (UE, OCDE, UNESCO); internamente, a legislação nacional (Constituição Portuguesa, Lei de Bases do Sistema Educativo, Avaliação das Escolas), mas, ainda, as recomendações do Conselho Nacional de Educação (CNE) (órgão independente da administração com funções consultivas e de apoio às políticas públicas de educação) e da própria Inspeção (GTAEE, 2011, p. 9 e 15). 
Tendo no seu mandato incluída a incumbência de "reapreciar os referenciais e a metodologia do Programa AEE” (PORTUGAL, Despacho 4150/2011, de 4 de Março), o GT de 2011 assumiu "uma visão global de continuidade" e uma "perspetiva de melhoria incremental e de consolidação do processo iniciado em 2006” (GTAEE, 2011, p. 12). Assim, na medida em que o modelo criado em 2006 resultara, como já referido, da articulação de múltiplos conhecimentos codificados, a versão de 2011 retoma essa natureza compósita e esse conhecimento 'fundador'. No entanto, algo de novo foi introduzido no modelo, como foi referido atrás. Ora essa novidade surge explicitamente associada à remissão para argumentos presentes em parecer elaborado pelo CNE, para a "experiência acumulada no ciclo de avaliação precedente" e para a reflexão produzida na IGE e por especialistas em avaliação em instituições de ensino (idem, ibidem; E1) (ROCHA, 2012, p. 306).Também na leitura do relatório se podem encontrar argumentos, problematizações e soluções associáveis a textos gerados em contextos não nacionais sobre o equilíbrio entre funções de prestação de contas e de melhoria ou sobre a articulação entre processos de avaliação externa e processos de avaliação interna, mormente pela SICI, desde a viragem do século (SICI, 2003; GRAY, 2014), e também pela OCDE (por, exemplo, SANTIAGO et al, 2012) ou mesmo em redes criadas no espaço europeu e com financiamento europeu para gerar e difundir conhecimento sobre as relações entre avaliações externas e internas (ver, por exemplo, SYNEVA, 2006).Porém, é notória a circunscrição dos argumentos que contam para apoiar as mudanças aos gerados por atores nacionais, tornando-se clara a 'indigenização’ da $\operatorname{argumentação~e~da~}$ implementação, e pela própria Inspeção, evidenciando sua endogeneização.

\section{As formas de validação social e cognitiva dos modelos}

Na criação do modelo, em 2006, houve um trabalho de articulação de pontos de vista no interior do GT e, mais importante, uma disseminação e discussão de variadas produções do GT (como os termos de referência, relatório de avaliação piloto, guião para apresentação das escolas, relatório de progresso e relatório final) com atores muito variados (políticos, profissionais, leigos) e em cerca de dezena e meia de iniciativas públicas (AFONSO; COSTA, 2011, p. 163-164). Já na revisão do modelo (2011) observa-se, no plano discursivo, uma consensualidade retoricamente fabricada, através da invocação adicional das fontes atrás mencionadas, as organizações internacionais e as "variáveis das escolas com mais impacto nas aprendizagens dos alunos" que identificam; a legislação nacional e sua "preconização" relativa às funções da avaliação no sistema educativo, o $\mathrm{CNE}$ e suas recomendações relativas aos "princípios" que regem as "escolas de 
qualidade", a própria Inspeção e as "boas práticas" que identifica como associadas às "escolas de qualidade" ("boas práticas" implicitamente decalcadas do próprio referencial de avaliação adotado no ciclo anterior) (GTAEE, 2011, p. 9, 21). Observa-se, ainda, já no plano processual, que a validação da nova proposta foi quase exclusivamente feita no interior do sistema de avaliação externa, através de inquérito feito a avaliadores e a diretores de nove agrupamentos de escolas e de três escolas não agrupadas participantes na experimentação do novo programa e no final da sua realização. Dos resultados dessa inquirição, por questionário, predominantemente composto por questões fechadas, foram elaboradas análises que sistematicamente reportam a "concordância com o modelo proposto" (ainda que nuances quanto ao grau dessa concordância, da "elevada" à "temperada"). Ademais, as conclusões extraídas revelam alterações menores (GTAEE, 2011, p. 35-39). Registe-se, ainda, que tendo sido feita a auscultação a "peritos" (na sua maioria, docentes de instituições do ensino superior ligados às áreas da Administração Educacional, da Avaliação, da Política Educativa), desta apenas ficam no relatório os registos de várias discordâncias dos mesmos, não atendidas: sobre o quadro conceptual (sobre a excessiva articulação entre avaliação externa e interna, sobre o "peso" e custo financeiro do modelo e seu contributo para a melhoria, sobre a uniformização do olhar sobre as escolas e a uniformização da própria AA das escolas, a ausência de observação de aulas). Em suma, as tendências para confinar internamente à administração os processos de revisão, bem como a indigenização e endogeneização do conhecimento, refletem-se nos processos de construção de acordos sobre o novo modelo e na sua validação.

\section{A HIBRIDAÇÃO DA REGULAÇAO: A REGULAÇÃO ESTRUTURADA PELO FLUXO DOS DOCUMENTOS TÉCNICOS}

A adoção da AEE, em 2006, foi um indicador da redefinição em curso do papel regulatório do Estado e de novas formas de regulação na educação. É incorporado na intensificação do processo de avaliação institucional, na busca de informações - sobre a "qualidade" das escolas e o sistema como um todo - para ser disponibilizado publicamente. Em Portugal, tradicionalmente, a avaliação externa tem sido associada à atividade de inspeção como um procedimento de controlo administrativo. Desde o final da década de 90, vem sendo progressivamente realizado um modelo baseado nas práticas de AA: a filosofia tradicional de questionamento está a enfraquecer e, em vez disso, os atores da escola são encorajados a se envolver e colaborar voluntariamente uns com os outros. Consequentemente, a AEE é utilizada como ferramenta de referência para avaliar 
a gestão das escolas, favorecendo uma política regulatória baseada em sanções sociais e processos de socialização, com o objetivo de criar novos e poderosos mecanismos de implementação de regras.

Durante a preparação do modelo de 2006, foi possível identificar a presença de fenómenos de hibridação nos documentos e nas intervenções dos atores (AFONSO; COSTA, 2012): por um lado, o novo papel da Inspeção, como uma organização que avalia a qualidade da Escola, está sendo apoiado por uma abordagem burocrática de regulação, pelo fato de a missão "tradicional" de Inspeção - que deve garantir que as escolas cumpram as regulamentações continuar a enquadrar o trabalho da instituição, não desaparecendo simplesmente com o surgimento de novos modos de regulação; por outro lado, notou-se a permanência, nas escolas, da perceção da Inspeção e dos seus membros como agentes de controlo e, consequentemente, uma interação regida por esse quadro cognitivo (AFONSO; COSTA, 2012). Por essa razão, colocou-se como hipótese a existência de uma mitigada transição de um estado mobilizador e negociador para um Estado supervisor e controlador, seguindo os termos de Lascoumes e Le Galès (2005).

A revisão de 2011 foi um 'espaço' de ação para a manifestação dessa tensão central e para a intensificação de processos de hibridação das modalidades de regulação, como seguidamente procuraremos mostrar, analisando a problematização e a preconização avançadas pelo GT, fortemente assentes no desenvolvimento de uma regulação baseada em documentos.

\section{'O' problema para a Inspeção: o impacto e a sequencialidade da AEE}

De acordo com as perceções avaliativas formuladas pelo CNE (2010) e, mais recentemente, pela OCDE (SANTIAGO et al.,2012), o impacto da AEE, durante o primeiro ciclo, foi débil no plano da sua consequência para a 'melhoria' das escolas e no plano da sua 'visibilidade' pública. O parecer do CNE (2010, p. 26153) refere-se à ausência de plano de ações de melhoria a ser "objeto de acompanhamento" por órgãos de administração das escolas e da administração educativa e recomenda a disseminação dos resultados, pelas escolas, na 'comunidade escolar' e, pela Inspeção, no espaço nacional, de modo a dar apoio aos decisores políticos e aos utentes "diretos e indiretos" do sistema escolar uma "leitura clara da qualidade dos estabelecimentos de ensino e apoio às suas escolhas". Por seu turno, os peritos da OCDE referem que "o impacto da avaliação externa é limitado", constatação que associam à ausência de uma "leitura alargada" dos relatórios produzidos pela IGE e à ausência de atividades de follow-up após a sua divulgação (SANTIAGO et al., 2012, p.110). Sublinham, também, a "insuficiente 
exploração" das práticas de divulgação de relatórios de AA como estratégia de envolvimento dos pais na vida escolar e notam que as consequências das práticas de AA são apreciadas como "muito difusas" e "dependentes do critério dos atores locais, especialmente do diretor (SANTIAGO et al., 2012, p. 109)

Essa debilidade é reconhecida pelo GT, que sublinha a necessidade de se evitarem processos avaliativos circunscritos a procedimentos administrativos e a utilização de instrumentos simples, que tenham verdadeiras consequências (GTAEE, 2011, p. 14). Como tal, preconiza a adoção de práticas conducentes à melhoria da escola as quais associa à sequencialidade dos processos avaliativos (idem, p. 10 e 49).

\section{A solução da Inspeção: articular documentos}

Nesse sentido, as soluções adotadas no segundo ciclo de AEE procuram fomentar essa 'sequencialidade' e, paralelamente, um maior alinhamento entre a AEE e a AA. Tal ocorre por três vias: reformatação de documentos associados ao processo (com revisões relativas a estrutura, conteúdos e estilo do documento 'apresentação da escola' e do 'relatório de AEE'); aumento do número de documentos associados ao processo (introdução de 'perfil de escola', introdução de documento 'plano de melhoria' (PM), elaboração de resposta escrita pela Inspeção ao 'contraditório' eventualmente apresentado pelas E/AE); reforço da articulação entre os documentos, ora através do alinhamento das categorias organizadoras da elaboração dos textos, ora pela imposição da presença em vários documentos de conteúdos ou de uma reflexão sobre conteúdos presentes noutros.

Cria-se, desse modo, uma cadeia de dependências entre produtos da AEE que, como adiante se clarificará, procura superar a débil articulação existente entre os documentos-chave usados no ciclo anterior (ver Fig. 3 e 4). A imaginação da melhoria do impacto da AEEE é, assim, feita em função da criação de sequências de produção-receção-produção de documentos formais (complementada pela obrigatoriedade da divulgação 'à comunidade', por parte de cada Agrupamento de escola/Escola, do Relatório de AEE e de PM). 
Figura 3 - Ciclo 2006-2010

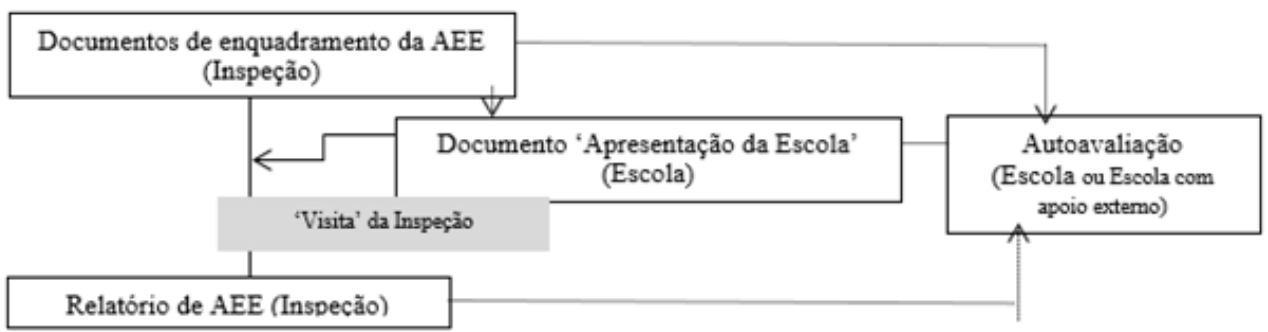

Figura 4 - Novo ciclo

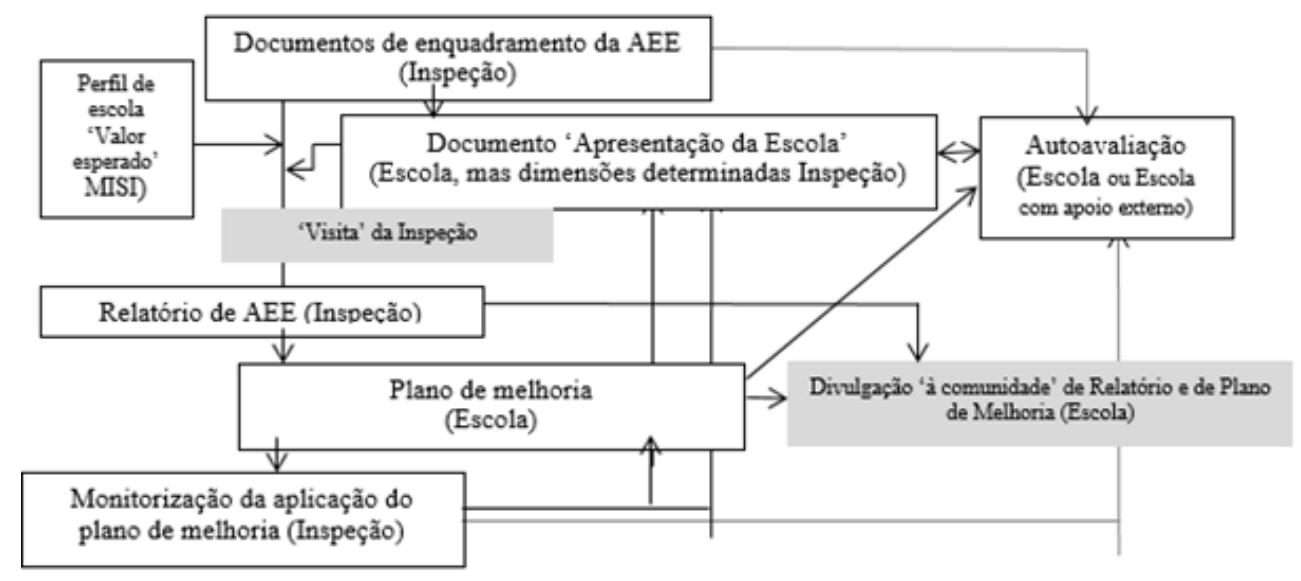

Dessas mudanças nos documentos, e na cadeia de relações de dependência entre documentos, centramo-nos, seguidamente, nas que associam a três deles: a apresentação livre, o PM, ambos elaborados pela E/AE, e o relatório da Inspeção. ${ }^{2}$

As especificações enviadas às $\mathrm{E} / \mathrm{AE}$ relativas ao formato e aos conteúdos do "Documento de Apresentação da Escola' foram alteradas. A principal mudança, justificada em nome da "simplificação e da coerência dos processos" e do "reforço da "complementaridade e do diálogo" entre AEE e AA, impõe que a E/AE "aborde explicitamente cada um dos campos de análise e domínios da avaliação externa” (GTAEE, 2011, p. 36,37, 44-45) que são fixados no quadro de referência da AEE elaborado pela Inspeção. Apresentado por um membro do GT, como "uma síntese do olhar que tinha de si mesma" (E1) (ROCHA, 2012, p. 308) e pelo relatório do GT como um "texto de interligação com a sua própria

2 Como se referiu atrás também é significativa a introdução do 'perfil de escola'. Apenas por razões de economia deste trabalho, não equacionamos a produção deste documento.

696 - RBPAE - v. 33, n. 3, p. 685 - 705, set./dez. 2017 
auto-avaliação", é esperado que, para além desta conformação ao racional da AEE, o documento se refira a "resultados de anteriores avaliações externas e medidas consequentes tomadas pela escola" (GTAEE, 2011, p. 44).

Em suma, o único documento elaborado pelas $\mathrm{E} / \mathrm{AE}$ para o arranque do processo de AEE deve resultar de uma tripla referenciação: ao quadro de referência e ao relatório da AEE anterior (elaborados ambos pela Inspeção) e ao PM elaborado pela escola, mas também este - como a seguir se verá - produzido em consonância com recomendações da Inspeção.

A introdução da obrigação de elaboração de um PM pelas E/AE, dois meses após a publicação do Relatório de AEE, pela Inspeção, é legitimada no parecer do CNE (2010) que recomenda "a obrigatoriedade de as escolas apresentarem um PM na sequência da AEE". Em todo o caso, a obrigatoriedade é apresentada pela Inspeção como indicativa da valorização da função que AEE, e a Inspeção, devem exercer sobre o trabalho desenvolvido nas escolas (ver GTAEE, 2011, p. 49-50): se "a efetividade da avaliação externa depende muito da apropriação dos resultados" e se às escolas se reconhece responsabilidade primeira pelo traçar de suas "linhas de ação", não deixa de competir à administração educativa uma intervenção "complementar" nessa matéria, se necessário através de uma "intervenção mais incisiva", como parece ser aqui o caso, de molde a garantir a "sequência" e a "consequência da avaliação externa".

Também aqui, o alinhamento com outros documentos é requerido, pois o PM é o lugar para a expressão de um "compromisso" com a concretização de ações "nas áreas identificadas na avaliação externa como merecedoras de prioridade no esforço de melhoria" (GTAEE, 2011, p. 50). Todo esse esforço de alinhamento não é estranho a um dos objetivos atribuídos à AEE, o de "validar" as práticas de autoavaliação das escolas" (op. cit., p. 42), no qual se percebe uma legitimação da função tutelar da primeira sobre a segunda.

Sintomaticamente, há a montante uma reformulação dos modos de apresentação do relatório de AEE. Este deve agora ser concebido à medida da preparação do PM ou como indutores do PM. Esta "peça que fica na escola" (Rocha, 2012, p. 312) é percebida como "um documento que se reveste de grande importância no Programa [de AEE]", pelo que deve ter efetivo impacto como "documento de análise e reflexão na escola" (E1). Para o GTAEE (2011, p. 55), a eficácia do documento exige que utilize "uma linguagem mais simples e directa", que seja mais conciso, menos descritivo e mais avaliativo. Mais importante, deverá ser "mais preciso na identificação das áreas onde a escola ou o agrupamento deve incidir prioritariamente os seus esforços de melhoria [...] [e que] ofereça elementos para a construção ou o aperfeiçoamento de planos de acção (...)" (GTAEE, (2011, p. 55). 
Mantendo-se fiel ao referencial da "qualidade", já norteador do ciclo anterior, perfilhando uma orientação de "continuidade", de aperfeiçoamento "incremental" e de "consolidação" do trabalho realizado entre 2006 e 2010, a revisão proposta pelo GTAEE e adotada pela Inspeção centra-se em matérias relativas à implementação do processo e a alterações deste resultantes e propiciadoras de maior impacto da AEE no sistema e sobretudo na vida das E/ AE. Ao fazê-lo, reequaciona matérias relativas à comunicação entre os 'mundos sociais' envolvidos nos processos de avaliação das escolas, fundamentalmente considerando a articulação entre produtos de avaliação e de planeamento - mais simplesmente, a articulação entre documentos.

A redefinição dessas (inter)dependências, concretizadas através da revisão da composição de documentos-chave e do estabelecimento de cadeias de relações entre documentos, constitui um modo de organizar a ação dos diversos intervenientes. Dito de outro modo, no âmbito do processo de AEE, a ordenação, a coordenação e o controlo da ação são organizados - não só, é certo, mas substantivamente - em função de sequências de produção-receção de documentos.

Pode-se, então, dizer que, para além dos episódicos encontros face a face que ocorrem durante as visitas da Inspeção no âmbito de cada ciclo de AEE com as escolas, a avaliação é efetivamente produzida na escrita dos documentos: a prática da avaliação das escolas é, em larga medida, uma prática de produção de documentos. $^{3}$ A partir desse ponto de vista, a intervenção reguladora da Inspeção procede, essencialmente, pela criação de uma cadeia entre documentos que desencadeiam ações à distância, em contextos organizacionais muito variados.

Ocorre que os documentos que vimos referindo têm uma ação sobre o passado e o futuro. Por um lado, os documentos (como a apresentação da escola, o relatório de AEE, o PM) servem para revelar e capturar o que ocorreu e ocorre nas E/AE. Nesse âmbito, ora expõem os desempenhos das escolas, cumprindo uma função de regulação de controlo pelos resultados, mas também dão visibilidade ao exercício da "autonomia clandestina" (BARROSO, 1997, p. 25) nas E/AE (nomeadamente na observação da dimensão 'Liderança, Gestão, Autoavaliação'), cumprindo uma função de regulação de controlo pela norma. Por outro lado, os documentos (sobretudo o novo PM, mas igualmente o Relatório

3 Nesta secção, seguimos muito de perto as perspetivas analíticas de Freeman (2006) e de Freeman e Maybin (2011) sobre o papel dos documentos nas políticas. 
de AEE) permitem determinar quer as ações do passado que permanecem suscetíveis de observação no futuro, quer a avaliação, no futuro, do cumprimento de ações acordadas como relevantes.

Ademais, através da criação dessa cadeia, fixa os atores locais num processo de comunicação ininterrupto, ainda que contingente (às posições e disposições dos atores, a fatores de contexto). Desse ponto de vista, os documentos não são apenas veículos de transmissão de informação, mas, também, lugares de construção de um vocabulário comum e da credibilidade (e vulgarização) de um certo conhecimento-poder avaliativo sobre as escolas.

Nesse sentido, o alargamento da documentação e a cadeia que se pretende criar entre produção-recepção-produção de documentos é reveladora de um problema (e de uma tentativa de solução para um problema) de comunicação entre dois mundos - o da Inspeção e o docente e entre as culturas de avaliação que habitam cada um desses mundos. Pensados segundo uma lógica de construção de uma relação de sequencialidade, a qual tem um centro regularizador na Inspeção, esses documentos parecem emergir como lugares para a difusão, estabilização e uniformização de um repertório técnico sobre avaliação. Esse repertório é, também, parte uma narrativa maior sobre a realidade escolar, na qual se vão conjugando definições e expectativas específicas sobre a qualidade das aprendizagens, a avaliação, a liderança a melhoria nas escolas.

Trata-se, então, de um exercício de regulação que se exerce nos planos cognitivo e normativo. Por exemplo, a compressão de três dos domínios da avaliação fixados em 2006 - Organização e Gestão Escolar, Liderança, e Capacidade de auto-regulação e melhoria da escola/agrupamento - em um único domínio apenas - Liderança e Gestão -, feita em nome da moderação "do peso das dimensões da organização e da gestão" (GTAEE, 2011, p. 22; E1), pode bem ser entendida como sinal de uma maior responsabilização e pressão, funcional e simbólica, sobre a ação dos diretores de E/AE, na medida em que esta é concebida como determinante para a variabilidade das duas outras dimensões da AEE: resultados dos alunos e prestação do serviço educativo. Sintomaticamente, a auto-avaliação da escola, anteriormente apreciada como uma dimensão autónoma da ação directiva (como uma capacidade do Agrupamento/escola) surge, agora, integrada à avaliação da ação directiva, da qual se esperam desempenhos que garantam: "coerência entre a auto-avaliação e a acção para a melhoria", "utilização dos resultados da avaliação externa na elaboração dos planos de melhoria", envolvimento e participação da comunidade educativa na auto-avaliação" e "continuidade e abrangência da auto-avaliação”(GTAEE, 2011). Esta associação da autoavaliação à ação directiva acompanha o 'mainstream' dos textos sobre autoavaliação e melhoria das escolas, quando estes sublinham a necessidade da institucionalização de culturas 
organizacionais nas quais a melhoria do ensino e dos resultados escolares depende do "fortalecimento da liderança aliada à avaliação externa, à auto-avaliação e prestação de contas” (SANTIAGO et al., 2012, p. 151).

A introdução da obrigatoriedade das escolas elaborarem PM mostra que a indução exercida pela Inspeção, no ciclo anterior, não se revelou suficiente para desencadear 'consequências' atribuíveis a sua intervenção reguladora. No entanto, esse retorno à regra compulsiva não significa o abandono dos standards - isto é, as "regras de aceitação voluntária, não mandatórias sobre como organizar, que práticas prosseguir, que serviços oferecer, como elaborar produtos (BRUNSSON; JACOBSSON, 2000, p. 2) - como recursos nucleares em todo o processo de regulação alavancado pela AEE. Portanto, o exercício da autoridade hierárquica continua a ser servido pela tecnologia da estandardização.

Por exemplo, as dimensões, os fatores e os referentes do quadro de referência da AEE, assim como os perfis de cada um dos níveis classificativos atribuídos às E/AE fixam regras relativas ao que 'ser', ao que 'ter' e ao 'que fazer' (ainda que não ao 'como fazer'). Ao estarem diretamente associadas ao principal documento que o E/AE apresenta no âmbito da preparação da AEE - simultaneamente, um texto no qual se espera ver revelada a capacidade de autoanálise de cada E/AE - esses referenciais adquirem um maior poder regulador das perceções descritivas e avaliativas dos atores locais. Também a determinação por parte dos avaliadores externos de áreas de melhoria a considerar pelos E/AE na elaboração dos seus planos de melhoria fixa o que cada organização tem de fazer, de ter ou de concretizar, assim como estabelece um conjunto de referentes para a prossecução das ações de monitorização a levar a cabo pelos atores da Inspeção.

\section{NOTAS FINAIS: A EXPANSÃO E RECONFIGURAÇÃO DA INTERVENÇÃO REGULADORA DA INSPEÇÃO}

As páginas anteriores mostram um ensaio de reconfiguração das relações entre os dois principais mundos atualmente envolvidos na avaliação das escolas, a Inspeção e os atores diretamente envolvidos na condução dos processos de avaliação das escolas (diretores e outros docentes). Nesse contexto, a revisão do modelo de AEE, em 2011,foi marcada por uma nítida preocupação com as consequências da AEE sobre a melhoria dos desempenhos escolares e os processos de administração e gestão das escolas. Essa busca de um maior impacto associa-se à adoção de um conjunto de alterações em documentos estruturantes do processo avaliativo e, sobretudo, à imaginação de uma cadeia de relações entre 
documentos de avaliação e de planificação, de modo a garantir uma articulação mais forte entre produção receção e uso desses documentos.

Ora, e paralelamente, observa-se um reequacionar das relações entre a AEE e a AA, deixando esta, mais do que antes, sob a tutela da primeira, como tem sido notado em estudos com forte recorte empírico (Sousa, 2014; Tristão, 2016) e em ensaios fundamentados (por exemplo, Lima, 2012; Afonso, 2015). Assim, a mais forte articulação entre documentos pode ser também compreendida como sinal do fortalecimento da AEE na sua condição de dispositivo de regulação das práticas de administração/gestão dos E/AE.

Concomitantemente, essa mais forte articulação sinaliza uma possibilidade de fortalecimento da presença da Inspeção entre as agências da administração central que operacionalizam a regulação institucional no campo educativo. Esse reforço da Inspeção como ator regulador revela-se na obrigatoriedade dos planos de melhoria e da atribuição à Inspeção de um mandato de monitorização de seu cumprimento. A conjugação 'plano-monitorização' expande o campo de ação da Inspeção na regulação da gestão das escolas: à já assumida intervenção no desencadear dos processos da 'prestação de contas', adiciona-se uma nova. associada à intervenção nos processos de 'melhoria da escola'. Trata-se, aliás, de prosseguir, no espaço nacional, uma norma partilhada com outras Inspeções, do espaço europeu: a da expansão da esfera de ação dessas tecnoestruturas da administração de educação, significativamente retratada em publicação da SICI, em cujo prefácio seu Presidente reaviva uma questão central que vem interessando seus membros - “o que acontece depois da inspeção?”(GRAY, 2014). Esta interrogação não pode ser desligada de uma questão que vem sendo apresentada como central, por vários atores sociais em Portugal, sobre o 'impacto da AEE' e a debilidade das atividades de follow-up. Não dispondo de mandato para intervir no "apoio às escolas" ou de "aconselhamento", a Inspeção poderá, agora, através do par 'plano de melhoria-monitorização do plano de melhoria' intervir junto às escolas como uma "estratégia para promover melhoria" - na linha do texto escrito, sobre Portugal, na referida obra (GRAY, 2014, p. 49).

Note-se, para finalizar, que a implicação das Inspeções europeias em ações associadas à ideia da 'melhoria da escola' é um 'compromisso' com mais de uma década, estabelecido desde a criação da SICI e confirmado em programas com financiamento europeu, orientados para a procura de articulação entre as práticas de AEE e de AA. No presente, essa articulação continua sendo vista como central, ainda que, agora, mais associada aos problemas dos impactos e do follow-up da AEE, como vimos, ou associada a uma expectativa de um circuito mais complexo de intervenções regulatórias, reforçando o papel da AA por via do aprofundamento da AEE, de modo a que o processo de AEE possa "tender, 
a médio prazo, para um programa de auditoria da qualidade da autoavaliação das escolas". (GTAEE, 2011, p. 13 e 45). Poder-se-á estar perante uma reconfiguração da Inspeção, distanciada da velha imagem de organização de controlo, mas igualmente afastada da marca de instância diretamente implicada na avaliação das escolas e da sua administração e gestão, simbolicamente reforçada pela associação a um status independente (a da auditoria) alcançado depois de promover formas de auto-organização e de autocontrolo nas escolas, sobre as quais exerceria, então, um poder verificador, próprio de uma organização que controla a uma maior distância. É uma imagem de uma entidade 'híbrida' que aqui se continua a desenhar.

\section{REFERÊNCIAS}

AFONSO, Almerindo J. Do desequilíbrio do pilar da autoavaliação no modelo de avaliação externa: apontamentos. In CNE, Avaliação Externa das Escolas. Lisboa: Conselho Nacional de Educação, 2015, p. 217-224.

AFONSO, Natércio; COSTA, Estela. La politique d'évaluation institutionnel d'écoles au Portugal. Recherches Sociologiques et Anthropologiques, $\mathrm{n}^{\circ} 2$, p 39-52, 2012.

AFONSO, Natércio; COSTA, Estela. Avaliação externa das escolas: um instrumento de regulação baseado no conhecimento, (155-189). In J. Barroso $\&$ N. Afonso (Org.). As políticas educativas em Portugal: mobilização de conhecimento e modos de regulação. Fundação Manuel Leão, 2011.

BRUNSSON, Niels; JACOBSSON, Bengt. The contemporary expansion of standardization. In Brunsson, N., Jacobsson, B. [and associates], A World of Standards (1-17). Oxford: Oxford University Press, 2000.

BARROSO, João. Les nouveaux modes de régulation des politiques éducatives en Europe. In Dutercq, Y. (dir.) Les Régulations des Politiques d'Éducation (151-171). Rennes, Presses Universitaires de Rennes, 2005.

BARROSO, João. Autonomia e Gestão da Escola. Lisboa, Ministério da Educação, 1997. 
BARROSO, João; CARVALHO, Luís Miguel; AFONSO, Natércio; FONTOURA, Madalena; COSTA, Estela. The social and cognitive mapping of policy: the education sector in Portugal. Research report, project KnowandPol, Orientation 1, 2008. Disponível em http:/ /www.knowandpol.eu

CARVALHO, Luís Miguel, As políticas públicas de educação sob o prisma da ação pública. Currículo sem Fronteiras, vol. 15, nº 2, 314-333, 2015.

CARVALHO, Luís Miguel; COSTA, Estela; AFONSO, Natércio. Espaces, acteurs et modalités de l'hybridation politique. Spirale - Revue de Recherches en Éducation, no 51, p. 15-30, 2013.

CNE - Conselho Nacional e Educação. Parecer 3/2010: Parecer sobre Avaliação externa das Escolas (2007-2009). Lisboa: Conselho Nacional de Educação,2010. Disponível em: http:// http://www.cnedu.pt/pt/deliberacoes/ pareceres? start $=10$

FREEMAN, Richard. The work the document does. Journal of Health Politics, Policy and Law, vol 31, n 1, p. 51-70, 2006.

FREEMAN, Richard; MAYBIN, J. Documents, practices and policy. Evidence \& Policy, vol. 7, no 2, p. 155-70, 2011.

GRAY, Adrian Supporting school improvement: the role of inspectorates across Europe. A report from the Standing International Conference of Inspectorates (SICI). Brussel: SICI, 2014. Disponível em : http:/ / http:/ /www. sici-inspectorates.eu/Activities/Development-and-Research/Research/TheRole-of-Inspectorates-Across-Europe

GTAEE. Propostas para um novo ciclo de avaliação externa das escolas. Relatório final. Lisboa, Ministério da Educação, 2011.

IGE. Avaliação Externa das Escolas. Referentes e instrumentos de trabalho, Lisboa, Ministério da Educação, 2006.

LASCOUMES, Pierre; LE GALÈS, Patrick. Introduction: understanding public policy through its instruments - from the nature of instruments to the sociology of public policy instrumentation, Governance, vol. 20, nº 1, p.1-21, january 2007. 
LASCOUMES, Pierre ; Le GALÈS, Patrick (dir.). Gouverner par les instruments. Paris: Presses de Sciences Po, 2005

LINDBLAD, Sverker; POPKEWITZ, Thomas. Educational restructuring. International perspectives ontravelling policies. Greenwich: Information age publishing, 2004.

LIMA, Licínio C. Elementos de análise organizacional das políticas e práticas de avaliação escolar. In WERLE, Flávia Obino Corrêa (org). Avaliação em larga escala: questões polémicas. Brasília: Liber Livro, 2012, p. 15-38.

MAROY, Christian. Convergences and hybridization of educational policies around 'postbureaucratic' models of regulation. Compare: A Journal of Comparative and International Education, vol. 39, n 1, p. 71-84, 2009.

OZGA, Jenny; JONES, Robert. Travelling and embedded policy, Journal of Education Policy, vol 21, no 1, p. 1-17, 2006.

PIETERSE, Jan Nederveen. Globalization as hybridization. In F. Lechner \& J. Boli (eds.). The Globalization Reader (99-105). Oxford. Blackwell Publishers Inc, 2000.

POPKEWITZ, Thomas. Globalization/Regionalization, knowledge, and the educational practices, In POPKEWITZ, T.S. (Ed.) Educational Knowledge (327). Albany, State University of NYP, 2000.

PORTUGAL, Despacho 4150/2011, de 4 de Março, Lisboa, 2011.

RIZVI, Fazal; LINGARD, Bob. Globalizing Education Policy. London, Routledge, 2009.

ROCHA, Patrícia. Que ruturas e que continuidades: do antigo para o novo ciclo de avaliação externa das escolas. Relatório de estágio. Mestrado em Ciências da Educação, Administração Educacional, IE-ULisboa, Dezembro de 2012. 
SANTIAGO, Paulo; DONALDSON, Graham; LOONEY, Anne; NUSCHE, Deborah.OECD Reviews of Evaluation and Assessment in Education: Portugal 2012. OECD Publishing, 2012.Disponível em: http://dx.doi. org/10.1787/9789264117020-en

SOUSA, A. (2014) Construções da autoavaliação de escolas. Discursos e sentidos. Tese de Doutoramento. Faculdade de Psicologia e de Ciências da Educação da Universidade do Porto.

SYNEVA - Quality Assurance through Synergy of Internal and External Evaluation of Schools. Examples of Interesting Practice of Internal and External Evaluation of Schools, 2006. Disponível em: https://www. openeducationeuropa.eu/en/project/synevanet

SICI (STANDING INTERNATIONAL CONFERENCE OF GENERAL AND CENTRAL INSPECTORATES OF EDUCATION). Effective School Self-Evaluation, 2003.Disponível em: www.edubcn.cat/rcs_gene/extra/05.../ plugin-essereport.pdf

STEINER-KHAMSI, Gitta, Understanding policy borrowing and lending, In G. Steiner-Khamsi and F. Waldow (eds.), World Yearbook of Education 2012: Policy Borrowing and Lending in Education, London: Routledge, 2012.

TRISTÃO, E. (2016). A autoavaliação como instrumento das políticas de avaliação externa das escolas. Tese. 2016, 294p. (Doutorado em Educação). Universidade de Lisboa, Lisboa, 2016.

ZANTEN, Agnès van; BALL, Stephen. Comparer pour comprendre: globalisation, reinterpretations nationales et recontextualisations locales, Revue de l'Institut de Sociologie, vol, $\mathrm{n}^{\circ}$ 4, p. 112-131, 2000.

LUíS MIGUEL CARVALHO é Professor Catedrático do Instituto de Educação da Universidade de Lisboa. E-mail: lmcarvalho@ie.ulisboa.pt

ESTELA COSTA é Professora Auxiliar doInstituto de Educação da Universidade de Lisboa. E-mail: ecosta@ie.ulisboa.pt 